NOTAS

\title{
A LA DOCTORA MILAGROS MIER, CON UN PROFUNDO RESPETO \\ Sergio Rodríguez*
}

Ahora se encuentra usted más allá del bien y del mal, donde es una con el mundo de las ideas, habiendo quedado inmortalizada en el pensamiento de decenas de personas que hoy nos encontramos reunidos para honrarla. Personalmente le agradezco el sólido entendimiento transmitido a través de sus apasionadas cátedras, en las cuales experimenté el exquisito pensamiento de decenas de pensadores que, como usted, han plasmado su rostro en la historia de la humanidad.

Me atrevo a decir que usted encarnó el ideal de este honorable Instituto, lo que un catedrático del ITAM debe tener: La suficiente objetividad para transmitir conocimiento aunada a la sutileza para imprimirle un esti-

* Licenciado en Administración de Empresas. También estudió los tres cursos de Ideas con ella. Actualmente trabaja en Mexicana de Aviación. lo propio al enseñar, volcando su propia personalidad en cada palabra y con el elegante toque de una dama con carácter.

Usted me comentó que quería que sus alumnos conocieran diferentes formas de instrucción, sin embargo algunos de nosotros decidimos tomar los tres cursos de Ideas con usted, y no fue en vano. De la mano con todas las técnicas administrativas que aprendí, se forjó la técnica más importante, la de cómo pensar con bases lógicas y humanas. Ahora sé que lo verdaderamente trascendental es la vida de la mente.

Con el más profundo respeto me despido sabiendo que no se encuentra lejos de nosotros, solamente en otro tiempo, en el momento donde las mentes maduras convergen. 